\title{
Transforming Traditional Teaching: A Professional Development Program for the College EFL Teachers*
}

\author{
Ming Li \\ School of Foreign Languages, Shanghai University of Engineering Science, Shanghai, 201620, China \\ Brett D. Jones \\ School of Education, Virginia Tech, Blacksburg, VA, 24061, USA
}

\begin{abstract}
Researchers have demonstrated the value of teacher professional development programs (PDPs) as an effective strategy to improve teaching. The purpose of our study was to design and test an intervention that could be used as part of a PDP with three English as a Foreign Language (EFL) teachers at a Chinese university. The primary aim of our intervention was to help the teachers implement teaching strategies that would motivate students to engage in learning, with the ultimate goal of improving student motivation and achievement. The strategies implemented in the classroom intervention included group presentation activities and a grading rubric. Through the use of both quantitative and qualitative research methods, we documented that the intervention had a positive effect on students' motivation and achievement, and changed teachers' attitudes and beliefs about how group activities could affect students' motivation and achievement.
\end{abstract}

Index Terms - teacher professional development program, group presentation, English as a Foreign Language Teaching, The MUSIC Model of Motivation

\section{INTRODUCTION}

Since the Opening Up and Reform Policy was initiated in China in 1978, learning the English language has gained considerable importance throughout China ( $\mathrm{Hu}, 2003)$. English serves as a primary indicator of the nation's development and is considered an essential personal asset (Gao, $\mathrm{Li}, \& \mathrm{Li}, 2002 ; \mathrm{Hu}, 2003)$. As a result, teacher professional development programs (PDPs) are becoming more significant, leading to higher quality education. Teacher training programs emerged in normal universities and colleges in China, along with other types of PDPs. Most shortterm PDPs involved workshops, seminars, and conferences, and the content of the PDPs was theoretical and researchorientated rather than involving practical classroom applications. Unfortunately, these types of PDPs were not very effective in improving teachers' instructional capabilities (Meng, Tajaroensuk, \& Seepho, 2013; Wen, 1989). For example, in one study, English as a Foreign Language (EFL) teachers reported that PDPs were impractical and that opportunities to attend PDPs were rare, which led them to suggest the following: (a) PDPs should be administered on campus every semester and should be supported by experts, (b) PDP instructors should be available when the teachers need help, (c) Instructors should work with a teaching team focusing on classroom practice, and (d) Administrators should work with teachers' schedules when organizing PDPs (Meng et al., 2013).

One problem with EFL teaching that we identified was that EFL teachers in China do not necessarily know how to motivate students and engage them in learning. For example, in one study about $97 \%$ of Chinese College EFL teachers agreed that teachers should create an active classroom environment for students' learning, yet $62 \%$ of the teachers reported spending their time lecturing in their classes Zhou (2005). In other words, most of the EFL teachers showed favorable attitudes toward active learning, but they did not know how to arrange their class effectively to do so. Given the ineffective implementation of PDPs and the fact that many EFL teachers are not implementing motivating, active learning strategies, we believed that there was an opportunity to design a PDP that could be used to motivate students by improving instruction in EFL classes.

\section{Purpose and Research Questions}

The purpose of our study was to design and test an intervention that could be used as part of a PDP with Chinese EFL teachers. The primary aim of our intervention was to help teachers implement teaching strategies that would motivate

\footnotetext{
* Funding: This paper was part of the achievement of the project entitled the Instructional reform for college-level English classes based on the national college education reform from the motivation perspective, and it was supported by Shanghai Foreign Language Education Press and China's Foreign Language Textbooks and Pedagogy Research Center with the grant No. 2018SH0037A. This paper was also part of the achievement of the project entitled First-class Discipline Construction of Foreign Language and literature and it was supported by Shanghai University of Engineering Science with the grant No. 2019XKZX011.
} 
students to engage in learning, with the ultimate goal of improving student motivation and achievement. Our research questions were as follows: (1) Can a professional development intervention have a positive effect on students' motivation and achievement? (2) Can a professional development intervention change teachers' attitudes and beliefs about how group activities can affect students' motivation and achievement? We did not have any preconceived ideas as to what the intervention would include because we wanted to address the needs of the students and teachers, which was only possible after surveying the students and interviewing the teachers. As we explain in more detail in the Method section (The intervention: Phase 4), the intervention consisted primarily of implementing student group presentation activities accompanied by a grading rubric. We hypothesized that this type of intervention would address students' lack of motivation for reasons explained in the Method section (see The intervention: Phase 4 for more explanation).

\section{THEORETICAL FRAMEWORKS}

\section{A. Teacher PDPs in the United States}

In the past two decades, much research related to teacher PDPs has been conducted in the United States (Desimone, 2009). Based on these studies, Desimone concluded that the core features of effective PDPs included: (a) the content focus, (b) the duration, (c) collective participation, (d) active learning, and (e) coherence (Desimone, 2009; Desimone, Smith, \& Ueno, 2006; Garet, Porter, Desimone, Birman \& Yoon, 2001). Furthermore, Desimone recommended a conceptual framework for PDPs that included these five core features because they can contribute to increasing teachers' knowledge and changing their beliefs. Such changes in knowledge and beliefs can then lead to enhanced instruction, which can improve student learning (Desimone et al., 2006; Firestone, Mangin, Martinez, \& Polovsky, 2005; Penuel, Fishman, Yamaguchi, \& Gallagher, 2007).

We hypothesized that Desimone's (2009) model of effective PDPs could be used as a guide for Chinese EFL teachers' PDPs. The focus on content could interest teachers in the PDP because they could learn practical knowledge and skills that could be applied in their classrooms. Collective participation and active learning could allow teachers to exchange and communicate actively with peers and educators, so that teachers could change their roles from passive listeners to active practitioners. In doing so, teachers' instructional capabilities may improve and their beliefs may change. The coherence between the PDP and school or district policies and reforms could allow teachers to realize the value of the PDP.

\section{B. The MUSIC Model of Motivation}

The MUSIC ${ }^{\circledR}$ Model of Motivation (MUSIC model; Jones, 2009, 2015) is a research-based model created by Jones (2009) to help instructors design instruction that motivates students to engage in learning. MUSIC is an acronym for strategies related to eMpowerment, Usefulness, Success, Interest, and Caring. Furthermore, using this model allows instructors to identify the problems in their teaching practices and then to redesign their instruction in ways that can motivate their students (Jones, 2009, 2015). The MUSIC model has been used in the United States in elementary schools (Jones \& Sigmon, 2016), middle and secondary schools (Parkes, Jones, \& Wilkins, 2015), and postsecondary schools (Jones, 2010; Jones, Epler, Mokri, Bryant, \& Paretti, 2013; Jones, Ruff, Snyder, Petrich, \& Koonce, 2012; Jones \& Skaggs, 2016; McGinley \& Jones, 2014), in Egypt with undergraduate students (Mohamed, Soliman, \& Jones, 2013), and in Iceland with middle school students (Schram, 2015). Because the MUSIC model has been used in other cultures, it is likely that it could also be helpful to teachers in China.

The empowerment component of the MUSIC model refers to teaching strategies that lead students to feel empowered about having the ability to control some aspects of their learning (Jones, 2009, 2015). Instructors can empower students by giving them choices and allowing them to make some decisions about their learning. The strategies related to the usefulness component of the MUSIC model help students understand why the content they are learning is useful for their short- and long-term goals. Instructors can help students understand the usefulness of the course content by explaining how it is useful to their lives and by designing activities that allow students to see the usefulness of the content. The success component of the MUSIC model includes teaching strategies that help students believe they can be successful if they put forth the effort. Instructors can increase students' perceptions of success by matching the difficulty levels of class activities with the abilities of the students and by giving specific feedback to students at regular intervals. The interest component of the MUSIC model includes strategies for interesting students in class activities and making the learning experience enjoyable. Instructors can interest students in course activities by getting them curious about some aspects of the content and by incorporating activities that arouse students' emotions. The caring component of the MUSIC model includes teaching strategies that help the instructor or other students care about students' learning and about them as a person (Jones, 2009, 2015). Teachers can demonstrate that they care for students by being approachable and by respecting students and ensuring that students in the class respect one another. The teaching strategies presented in this section are merely examples; they are not intended to be a comprehensive list of all available strategies to implement the MUSIC model. For many more examples, please see Jones (2009, 2015) and www.theMUSICmodel.com.

\section{METHODOLOGY}


In this section, we describe the participants and the intervention that we implemented. The study was approved by the Institutional Review Board (IRB) at the authors' university; the participating Chinese university did not require IRB approval.

\section{A. Teacher Participants}

The first author provided information about this professional development intervention to teachers in the department of College English in a Chinese university. Three EFL teachers, John, Jade, and Luis (pseudonyms), agreed to participate in this intervention voluntarily. We accepted three EFL teachers as participants because (a) they were College English instructors, which was the target population of this study; (b) College English is a prominent course for all freshmen and sophomores in Chinese universities; (c) College English instructors play an important role in EFL teaching on campus; (d) they were available for the duration of the intervention, and (e) they differed with respect to gender (Jade is female, and John and Luis are male), age $(M=32, S D=2.5)$, and teaching experience (Jade had six years of teaching experience, John had four years, and Luis had 10 years).

\section{B. The Intervention: Phase 1, Two Meetings Concerning Introduction to This Intervention}

The three EFL teachers attended two training meetings with the first author that were held during the first week of a Spring semester. The purpose of the first training was to introduce an outline of the PDP intervention. The Chinese teachers were also introduced to the American researcher (the second author) in order to increase familiarity and trust. We explained the significance of the intervention to the teachers' own development and to the university's mission as a means to explicitly demonstrate the coherence between the intervention and their school policies.

The purpose of the second meeting was to introduce the MUSIC model (Jones, 2009, 2015) and the MUSIC Inventory (Jones, 2016). To assess the validity of the survey that they were going to administer to their students, we shared a Chinese version of the survey which was translated following the process of initial translation, back translation, and a third bilingual translation revision. The survey consisted of the 26-item MUSIC Inventory (see the User Guide at Jones, 2016, for a full description of the MUSIC Inventory), a 4-items effort scale (from Jones, 2010; based on Plant \& Ryan, 1985), one teacher rating item, and one course rating item. The MUSIC Inventory and effort items were measured on a Likert-format scale ranging from 1 (Strongly disagree) to 6 (Strongly agree). The teacher and course rating items were measured on a Likert-format scale ranging from 1 (Terrible) to 6 (Excellent). The teachers agreed that these survey items were appropriate for their students. The first author trained the teachers how to administer the paper copy of the inventory to their students and explained what they should do with the surveys after they were collected.

\section{The Intervention: Phase 2, Collected Data from Students and Interviewed Teachers}

Each of the teachers chose one of their classes to participate in this research study and gave students the survey at the beginning of the class in the second week. To allow us to compare the pre-survey and post-survey, the teachers asked the students to write their campus passport number and their last term score (pre-test score) in the bottom right corner of the second page of the survey after they answered all the questions. After collecting the data, the teachers entered the data into a spreadsheet and sent it to the first author. The first author then interviewed each teacher individually via Skype for about 30 minutes. The interview included questions such as Explain any changes in how you viewed yourself as a teacher before this research and how you view yourself as a teacher now. The purpose of the interview was primarily to determine why the teachers wanted to participate in the intervention and what they hoped to gain by participating.

\section{The Intervention: Phase 3, Analyzed Data and Recommend Strategies to the Teachers}

During the third week, we analyzed the data and identified potential areas of improvement, similar to the process described in Jones (2015). Analyzing the quantitative data from the survey and the qualitative data from the interviews, we found that (with respect to the five MUSIC model components) most students were less motivated in their English course with respect to empowerment, success, and interest. The coded themes from the interviews were consistent with the data from the survey and indicated that teachers worked hard to create the lesson plans and lectured about the content knowledge. However, the teachers perceived the class environment to be tedious and the students to be fairly inactive. Based on these findings, we selected strategies consistent with the MUSIC model that focused on four of the MUSIC components (i.e., empowerment, success, interest, and caring) by incorporating student group presentation activities accompanied by grading rubrics. We did not focus specifically on the usefulness MUSIC component in the intervention because the usefulness of learning English was obvious to all students.

\section{E. The Intervention: Phase 4, Ten Weeks of Group Presentation Activities in Class}

The group presentation activities lasted 10 weeks, from week four to week 13. In week four, the teachers explained the group presentation activities. First, students were randomly assigned to groups of six and were asked to select a group leader. Second, students were given an assignment along with a grading rubric that specified how they would be assessed on it. Third, the assignment involved group member interactions and student-led presentations. The presentation material was based on the course readings. Fourth, the students were asked to outline the text and check the quality of their understanding with their instructor. Part of the assignment was to present the material to their classmates. 
Fifth, each group member was required to speak a few sentences during the presentation. The teacher was available to students both inside and outside of the classroom when the students sought help with their presentations.

We hypothesized that allowing students to work in groups would increase their perceptions of empowerment because they would have more control over their learning, as opposed to simply listening to the teacher lecture. We reasoned that the grading rubric would provide clear expectations for students, which could increase their perceptions that they could be successful (Jones, 2015). We also expected that students would find the group presentation activities more interesting than lecture because it was a novel teaching approach to them and it added variety to the traditional lecture class format. It also provided more opportunities for interesting discussion and conversation both between peers and between teachers and students. Finally, we hypothesized that the group activities would improve students' perceptions of caring because it showed that the teacher cared enough to try a new approach to help students learn and because both the teachers and other students had an opportunity to help one another during the group activities. In fact, help was available to students both inside and outside of classes.

\section{F. The Intervention: Phase 5, Collected Data from Students'Survey and Teacher Interviews}

The teachers conducted the survey of students' perceptions of the group presentation activities in week 13, one week before the final exam week. After the semester ended, the teachers added each student's final exam score (which we have labeled as the "post-test score") to their post-survey. This post-test score represents a student's score on a standardized test that assessed students' English proficiency.

After the teachers sent all the survey data to us, they participated in a second interview in which they were asked to reflect on the strengths and weaknesses of the group presentation activities. We asked them questions about their perceptions of the changes in their classroom environment. For example, two of the questions were as follows: (1) "Explain how participating in this intervention has changed your classroom teaching. Provide examples whenever possible." and (2) "Explain any changes in your students due to the group activities. Provide examples whenever possible."

\section{RESUlTS AND DisCUSSION}

\section{A. Research Question 1: Effects on Students' Motivation and Achievement}

Our first research question was: Can a professional development intervention have a positive effect on students' motivation and achievement? We conducted paired $t$-tests on all the quantitative variables, including empowerment, usefulness, success, interest, caring, effort, course rating, teacher rating, and course grade. The findings indicated that there was a significant increase in all variables between the pre-survey and the post-survey scores $(p<.05$; see Table 1) and from the pre-test $(M=65.7, S D=13.4)$ to the post-test $(M=78.6, S D=7.9)$, mean difference $=12.9, t=12.41, d f=$ $155, p<.001$.

TABLE 1

MEANS, StANDARD DEVIATIONS, AND T-TEST RESUlts For THE VARIABLES

\begin{tabular}{|c|c|c|c|c|c|c|}
\hline Variable & $\begin{array}{c}\text { Pre-survey } \\
M(S D)\end{array}$ & $\begin{array}{c}\text { Post-survey } \\
M(S D)\end{array}$ & Mean Difference & $t$ & $d f$ & $p$ \\
\hline Empowerment & $3.99(0.86)$ & $4.52(0.72)$ & 0.53 & 6.77 & 155 & .000 \\
\hline Usefulness & $4.69(0.78)$ & $4.97(0.73)$ & 0.28 & 3.46 & 155 & .001 \\
\hline Success & $3.87(0.99)$ & $4.34(0.87)$ & 0.47 & 4.42 & 155 & .000 \\
\hline Interest & $3.82(0.80)$ & $4.42(0.73)$ & 0.60 & 7.15 & 155 & .000 \\
\hline Caring & $4.07(0.77)$ & $5.06(0.72)$ & 0.99 & 12.61 & 154 & .000 \\
\hline Effort & $4.02(0.97)$ & $4.32(0.89)$ & 0.30 & 2.97 & 155 & .003 \\
\hline Teacher rating & $4.96(0.96)$ & $5.19(0.76)$ & 0.23 & 2.42 & 155 & .017 \\
\hline Course rating & $4.31(1.23)$ & $4.78(0.86)$ & 0.47 & 4.01 & 155 & .000 \\
\hline
\end{tabular}

The fact that all five MUSIC components increased from the pre-survey to the post-survey is consistent with our hypothesis that the intervention would increase students' perceptions of empowerment, success, interest, and caring. These findings indicate that the intervention worked as designed to improve students' motivation-related perceptions. Our results do not provide us with information that can be used to determine why students' perceptions increased; however, we hypothesize that they increased for the reasons that we provided previously in The intervention: Phase 4 section. That is, the group presentation activities were more consistent with teaching strategies derived from the MUSIC model (Jones, 2009, 2015). 
Although we did not hypothesize that usefulness would increase, it increased as well. This finding suggests that students perceived the group presentation activities to be more useful to their lives than traditional teaching. And finally, students' test scores increased, possibly because they were more motivated and engaged in their learning, which led them to use more effective learning strategies. Further researchers could examine whether students actually used different strategies or not, and if so, they types of strategies that they used.

The students' responses are consistent with the teachers' responses obtained from the interviews. After collecting the interview data, the first author coded the data twice, first by the key words and second by identifying themes across the data. We identified a few themes related to the changes in the classroom environment. In the traditional lecture class, students were passive receivers of content knowledge. Note taking was the primary mans through which students engaged in the class. Teachers were class leaders, major speakers, and important directors. Students in these lecture classes appeared to be bored. In contrast, during the group presentation activities in the intervention, students became active presenters, engaged learners, and problem solving agents in the coursework. Students had more power and felt much more excited. Teachers changed into listeners, commenters, and major managers in the class. Therefore, the class was perceived as fresh and interesting. These changes in the classroom environment indicated that the intervention included effective instructional strategies that motivated students.

\section{B. Research Question 2: Changes in Teachers' Attitudes and Beliefs}

Our second research question was: Can a professional development intervention change teachers' attitudes and beliefs about how group activities can affect students' motivation and achievement? Responses to our interview questions revealed that significant changes had taken place in the Chinese teachers' attitudes and beliefs. The following responses from the teachers indicate that through this intervention, they began to realize the advantages of group presentation activities for students' motivation and learning. In the remainder of this section, we provide the teachers' reflections on their new attitudes and beliefs. John reported the following:

Before this program, I had doubts about whether my students could give a good presentation in class. I did not give them enough credit. However, from this intervention, I found that some students really have done an excellent job. Furthermore, their presentations have exceeded my expectation. In fact, at times, I had such an idea about the studentcentered teaching style, but I didn't know how to design and put it into practice. From this intervention, I know how to manage a student-centered class.

Before this intervention, I believed that the lecture class was very effective. The teacher was the speaker in class and, I thought, only in this way the students could master the content. From this program, I realize that the teacher should allow the students to be the focus and have the major roles in class. The teacher should hold a less important role in class. At the same time, the teacher should act as a director for a movie, guiding and managing the whole process effectively.

The second teacher, Luis, attended many training programs and accumulated rich teaching experiences. He stated the following during his interview.

Participating in this intervention brought many changes into my class teaching. Before this intervention, it was a typically traditional lecture class. The class ran as follows: the vocabulary, the lead-in activity, brief reading, intensive reading, and the exercises. I believe the lecture class is typical in College English course across China. I have watched many videos of national College English teaching contests. Most of them followed this traditional lecture style. The only differences amongst the winners were their preparation of the contents and the reading materials.

When I participated in this intervention, my class became student-centered. The students' presentations on new vocabulary and intensive reading accounted for most of the class time. After the presentation, I usually commented on their performance. In sum, my role of the teacher has changed. Before this program, I was the main speaker and manager in class. With this program, I became its listener and commenter. Based on this, you can see that my class has changed in terms of the content and form.

Jade had taught College English for six years after she graduated with her Master Degree in Applied linguistics. Before this intervention, she once attended two conferences in Xi'an and Beijing, but she said she was not satisfied with them. She thought the lectures were isolated from classroom practice and they could not solve her teaching problems. She was excited to have heard about the opportunity to participate in this intervention and she stated the following.

This intervention transformed my teaching mode. Before this program, my class was a typical lecture course: I spoke in front of the classroom; the students listened, took notes, and answered my questions. They were relatively passive learners. This program is student-centered. Their group activities are diverse and flexible, and they make up a majority of the class. Thus, the students are more engaged than before. Before this program, I held the traditional teaching strategy: teachers were leaders of the class and should provide lectures. After participating in this program, I realized the teachers should be both guides and participants in the class.

The responses by all of the teachers indicate that they had changed their attitudes and beliefs about how it was possible to motivate students through empowering them with group presentation activities. Their comments demonstrate that after the intervention they saw the value in giving students some control and that their teaching role can change from a lecturer to a facilitator or guide.

\section{Limitations and Future Research}


Although the quantitative and qualitative data suggest that the professional development intervention was successful at motivating students and changing teachers' attitudes and beliefs, we believe that it is possible to improve upon the intervention and that further research is needed to understand how to effectively implement these types of interventions. In this section, we will highlight some of these possibilities.

During the interviews with the three teachers, they reported that some students were less motivated and seldom performed actively in the group discussions and presentations. This finding showed that it was necessary for teachers to teach students the skills on how to be active learners in group activities, such as collaboration (social support and trust), communication, and problem solving (Christie, Tolmie, Thurston, Howe, \& Topping, 2009; Galton, 1990; Kutnick \& Manson, 1998). Given that the traditional lecture method is used in schools from elementary to postsecondary schools in China, some of the Chinese students may lack the necessary interpersonal and critical thinking skills needed to participate effectively in class activities involving group activities. In the future, practitioners and researchers could consider what types of social skills training are necessary for students before they are asked to participate in group activities.

Another consideration is the necessity of detailed training for the teachers in how to implement group work. We trained the teachers in the general framework of group activities, such as the random assignment of students, the group task, a group leader, and the presentation grading rubric. We found that these strategies were appropriate for a college EFL class; however, other factors may need to be considered for teachers in other types of classes and content areas, such as training related to class seating arrangements, group size, the number of groups, group stability, and group composition (Blatchford, Kutnick, Baines, \& Galton, 2003).

Although the three EFL teachers confirmed that group activities were effective in motivating students, they had some concerns about empowering students. They worried that it would take more time to finish one unit of their teaching plan if students became the presenters in class. Also, in implementing the intervention that allowed for student presentations, it was difficult to follow the syllabus designed by the college. They seemed to lack the confidence needed to implement this type of pedagogy within their college structure. It could be interesting to examine the coherence between the intervention and the school policies and reforms, as suggested by Desimone (2009), to determine how school policies can help or hinder teachers' adoption of different instructional strategies.

\section{CONCLUSION}

We documented that it is possible to design an intervention consistent with Desimone's (2009) model of PDPs and Jones' (2009, 2015) MUSIC Model of Motivation in ways that can have a positive effect on students' motivation and achievement. The results showed that when students participated in group presentation activities, they rated their perceptions of empowerment, usefulness, success, interest, caring, effort, teacher rating, and course rating higher than when they received traditional lecture instruction. In addition, their grades at the end of the semester improved over the prior semester. Furthermore, by implementing this intervention as part of a professional development experience, the teachers changed some of their attitudes and beliefs about how group activities could affect students' motivation and achievement. In fact, some of the students exceeded their expectations about what was possible. Future implementations of this type of interventions can build on these initial successes to meet the needs of other teachers in other content areas.

\section{REFERENCES}

[1] Blatchford, P., Kutnick, P., Baines, E., \& Galton, M. (2003). Toward a social pedagogy of classroom group work. International Journal of Educational Research, 39(1), 153-172. doi:10.1016/S0883-0355(03)00078-8.

[2] Christie, D., Tolmie, A., Thurston, A., Howe, C., \& Topping, K. (2009). Supporting group work in Scottish primary classrooms: improving the quality of collaborative dialogue. Cambridge Journal of Education, 39(1), 141-156.

[3] Desimone, L. M. (2009). Improving impact studies of teachers' professional development: Toward better conceptualizations and measures. Educational Researcher, 38(3), 181-199. doi:10.3102/0013189X08331140.

[4] Desimone, L. M., Smith, T., \& Ueno, K. (2006). Are teachers who need sustained, content-focused professional development getting it? An administrator's dilemma. Educational Administration Quarterly, 42(2), 179-215.

[5] Firestone, W., Mangin, M., Martinez, M., \& Polovsky, T. (2005). Leading coherent professional development: A comparison of three districts. Educational Administration Quarterly, 41(3), 413-448.

[6] Galton, M. (1990). Grouping and groupwork. In C. Rogers \& P. Kutnick (Eds.), The social psychology of the primary school. London: Routledge.

[7] Gao, Y., Li, Y., \& Li, W. (2002). EFL learning and self-identity construction: Three cases of Chinese college English majors. Asian Journal of English Language Teaching, 12(2), 95-119.

[8] Garet, M. S., Porter, A. C., Desimone, L., Birman, B. F., \& Yoon, K. S. (2001). What makes professional development effective? Results from a national sample of teachers. American Educational Research Journal, 38(4), 915-945. doi:10.3102/00028312038004915.

[9] Hu, G. (2003). English language teaching in China: Regional differences and contributing factors. Journal of Multilingual and Multicultural Development, 24(4), 290-318.

[10] Jones, B. D. (2009). Motivating Students to Engage in Learning: The MUSIC Model of Academic Motivation. International Journal of Teaching and Learning in Higher Education, 21(2), 272-285.

[11] Jones, B. D. (2010). An examination of motivation model components in face-to-face and online instruction. Electronic Journal of Research in Educational Psychology, 8(3), 915-944. 
[12] Jones, B. D. (2015). Motivating students by design: Practical strategies for professors. Charleston, SC: CreateSpace.

[13] Jones, B. D., Epler, C. M., Mokri, P., Bryant, L. H., \& Paretti, M. C. (2013). The effects of a collaborative problem-based learning experience on students' motivation in engineering capstone courses. Interdisciplinary Journal of Problem-based Learning, 7(2), 34-71.

[14] Jones, B. D., Ruff, C., Snyder, J. D., Petrich, B., \& Koonce, C. (2012). The effects of mind mapping activities on students' motivation. International Journal for the Scholarship of Teaching and Learning, 6(1) 619-626.

[15] Jones, B. D., \& Sigmon, M. L. (2016). Validation evidence for the elementary school version of the MUSIC ${ }^{\circledR}$ Model of Academic Motivation Inventory. Electronic Journal of Research in Educational Psychology, 14(1), 155-174. Retrieved from http://dx.doi.org/10.14204/ejrep.38.15081.

[16] Jones, B. D., \& Skaggs, G. E. (2016). Measuring students' motivation: Validity evidence for the MUSIC Model of Academic Motivation Inventory. International Journal for the Scholarship of Teaching and Learning, 10(1), 1-9. Retrieved from http://digitalcommons.georgiasouthern.edu/ij-sotl/vol10/iss1/7.

[17] Kutnick, P., \& Manson, I. (1998). Social life in the classroom: towards a relational concept of social skills for use in the classroom. The social child, 165-182.

[18] McGinley, J., \& Jones, B. D. (2014). A brief instructional intervention to increase students' motivation on the first day of class. Teaching of Psychology, 41(2), 158-162.

[19] Meng, J., \& Tajaroensuk, S. (2013). An investigation of tertiary EFL teachers' problems in their in-service professional development. Journal of Language Teaching and Research, 4(6), 1356-1364. doi:10.4304/j1tr.4.6.1356-1364.

[20] Mohamed, H. E., Soliman, M. H., \& Jones, B. D. (2013). A cross-cultural validation of the MUSIC Model of Academic Motivation and its associated inventory among Egyptian university students. Journal of Counseling Quarterly Journal, 36, 2-14.

[21] Parkes, K., Jones, B. D., \& Wilkins, J. (2015). Assessing music students' motivation using the MUSIC Model of Academic Motivation Inventory. UPDATE: Applications of Research in Music Education. Advance online publication.

[22] Penuel, W. R., Fishman, B., Yamaguchi, R., \& Gallagher, L. P. (2007). What makes professional development effective? Strategies that foster curriculum implementation. American Educational Research Journal, 44(4), 921-958.

[23] Plant, R. W., \& Ryan, R. M. (1985). Intrinsic motivation and the effects of self-consciousness, self-awareness, and egoinvolvement: An investigation of internally-controlling styles. Journal of Personality, 53(3), 435-449.

[24] Schram, A. B., (2015). Validating an Icelandic version of the MUSIC Model of Academic Motivation Inventory (Unpublished doctoral dissertation). Virginia Tech, Blacksburg, VA.

[25] Wen, H.J. (1989). Brief introduction to teacher training. Beijing: Beijing Teacher's University Press

[26] Zhou, Y. (2005). Needs analysis of EFL teacher development in Chinese universities, Foreign Language Teaching and Research, 37(3), 206-210.

Ming Li (bahalucy@163.com) is an associate professor in the School of Foreign Languages at Shanghai University of Engineering Science in China, and she received her PhD in Educational Psychology at Virginia Tech. Her research interests include Teaching English as a Foreign Language, student academic motivation and teachers' professional development.

Brett D. Jones, PhD (brettdjones@gmail.com), is a professor of Educational Psychology at Virginia Tech, Blacksburg, Virginia. He received his doctoral degree in Educational Psychology from the University of North Carolina at Chapel Hill. His research includes examining methods instructors can use to design environments that support students' motivation and learning (see http:// www.theMUSICmodel.com). 